\title{
ARTE RUPESTRE EN ASENTAMIENTOS DEL PERÍODO TARDÍO EN LOS VALLES DE LLUTA Y AZAPA, NORTE DE CHILE
}

\author{
ROCK ART IN LATE HORIZON SETTLEMENTS IN THE VALLEYS \\ OF LLUTA AND AZAPA, NORTHERN CHILE
}

\author{
Daniela Valenzuela*, Calogero M. Santoro** y Álvaro Romero*
}

\begin{abstract}
Este trabajo busca contribuir a la discusión sobre el proceso de expansión del estado Inka hacia las áreas periféricas del sur de los Andes, particularmente en los valles costeros Lluta y Azapa del extremo norte de Chile. Este proceso es analizado explorando el rol del arte rupestre -como soporte material de transmisión de ideología- en el proceso de integración que experimentaron las poblaciones locales de los valles de Lluta y Azapa ante el arribo de la influencia incaica. Se busca responder si existe en el área de estudio un arte rupestre que pueda ser reconocido como Inka, y cómo éste se relaciona con el proceso de expansión del estado Inka.

Se analizan tres sitios habitacionales con presencia de bloques grabados, ocupados durante el período Tardío o Inka (1.400-1.530 d.C.): Millune y Vinto en el valle de Lluta y Achuyo en el valle de Azapa. Sobre la base de diferencias formales del arte rupestre relacionadas con variaciones en la composición de componentes cerámicos, arquitectura y organización del espacio de los sitios, postulamos la existencia de un patrón de arte rupestre de origen local pre-Inka, que es transformado y utilizado por el Inka de acuerdo a los intereses imperiales de expansión ideológica y control de esta provincia. Concluimos que uno de los cambios más notorios provocados por el orden Inka ocurre en la transformación formal del arte rupestre local y su uso en espacios públicos.
\end{abstract}

Palabras claves: Arte rupestre, asentamientos habitacionales, expansión Inka.

This paper intends to contribute to discussion of the Inka state expansion toward the peripheral areas of the southern Andes, including the Lluta and Azapa coastal valleys, northern Chile. This process is analysed through exploration of the role of rock art - as a material medium for ideological transmission-in the Inka integration of local populations. We try to demonstrate whether it is possible to recognize an Inka rock art and how this was related to the Inka expansion.

We analyse three small residential sites, which include engraved stones and were occupied, at least, during the Late period (ca. 1300-1450 A.D.). Millune and Vinto are in the Lluta valley and Achuyo is in the Azapa valley. Based on differences in the formal attributes of the rock art, and associated features such as decorated pottery, architecture and spatial organization of the rock art, we postulate the existence of a local and pre-Inka rock art style. This style was transformed and utilized by the Inka state as an ideological tool, based on their imperial interest, for the conquest and control of this province. We conclude that the most remarkable change took place in the conversion of formal aspects of the local rock art style to more standardized, Inka style, and in the relocation of the rock art scenario from private to public spaces.

Key words: Rock art, settlements, Inka expansion.

En la discusión del proceso de expansión del estado Inka hacia las áreas periféricas del sur de los Andes se ha enfatizado la arquitectura y cerámica como indicadores arqueológicos del proceso. Sin embargo, considerando al Tawantinsuyu como una formación política dinámica que se sirvió de variados mecanismos de expansión y control, diversas expresiones de la materialidad incaica, como el arte rupestre, pueden ser vistas como instrumentos de corte ideológico que sirvieron en el proceso de conquista y consolidación del estado (D’Altroy 1992; Niles 1993; Uribe y Adán 1999, 2004). En este sentido, el estudio del arte rupestre aparece como una vía relevante para entender el proceso de expansión del Tawantinsuyu, considerando que es frecuentemente descrito como asociado a sitios de filiación Inka en diversas partes de los Andes Centro Sur (cf. Albarracín Jordán 1991; Fernández Distel 1974, 1976; Gallardo y Vilches 1995; Gallardo et al. 1999; Gordillo 1992; Hernández Llosas 2003; Hyslop 1990; Krapovikas 1961; Linares Málaga 1968; Meyers 1998; Muñoz et al. 1987; Ruiz et al. 2001; Santoro y Muñoz 1981; Vilches y Uribe 1999; Uribe et al. 2000), así como también en los Andes Septentrionales (Haffernan 1996; Schjellerup 1998), Andes Meridionales (As-

\footnotetext{
* Departamento de Arqueología y Museología, Universidad de Tarapacá, Chile.dpvr@yahoo.com, aromero@uta.cl

** Centro de Investigaciones del Hombre en el Desierto y Departamento de Arqueología y Museología, Universidad de Tarapacá, Casilla 6-D, Arica, Chile. csantoro@uta.cl
} 
chero 2000; Podestá 1997; Williams 2003) y mucho más al sur como la zona central de Chile y Argentina (Troncoso 2003; Schobinger 2003). Asimismo, debemos subrayar la tradición incaica de rocas esculpidas en los Andes Centrales destacada por diversos autores (Haffernan 1996; Hosting 2002; Husson 1998; Núñez Jiménez 1986; Uhle 1998 [1913]; van de Guchte 1984, 1999).

Estas evidencias no pueden ser soslayadas, por lo tanto la explicación del rol de este registro en el contexto incaico es cada vez más problemático y necesario para entender con mayor profundidad la dinámica de expansión e integración de las poblaciones locales al estado Inka. Esto adquiere mayor relevancia cuando se reflexiona en el empleo de diversas expresiones materiales por parte del Tawantinsuyu para extender su dominio.

Siguiendo esta línea, analizamos tres sitios habitacionales con arte rupestre de los valles de Lluta y Azapa, del extremo norte de Chile, ocupados al menos durante el período Tardío o Inka (ca. 1.400-1.530 d.C.). Con esto pretendemos abordar el problema de la identificación de un arte rupestre incaico y cómo se relacionaría con el proceso de expansión del estado. En este contexto, exploramos el rol del arte rupestre -como soporte material de transmisión de ideología- en el proceso de integración que experimentaron las poblaciones locales de los valles de Lluta y Azapa ante el arribo de la influencia incaica. Hablamos de proceso de integración porque involucró diferentes entidades sociales (grupos locales, grupos de tierras altas y el estado Inka) que interactuaron de acuerdo a sus propios intereses y posibilidades, insertas dentro de un proceso político mayor ocurrido a escala regional y que trajo consigo una serie de cambios sociales.

\section{Área de Estudio}

Los valles de Lluta y Azapa se ubican en la vertiente occidental de los Andes en el extremo norte de Chile (Figura 1). El ambiente es desértico sin precipitaciones locales, por lo que la disponi-

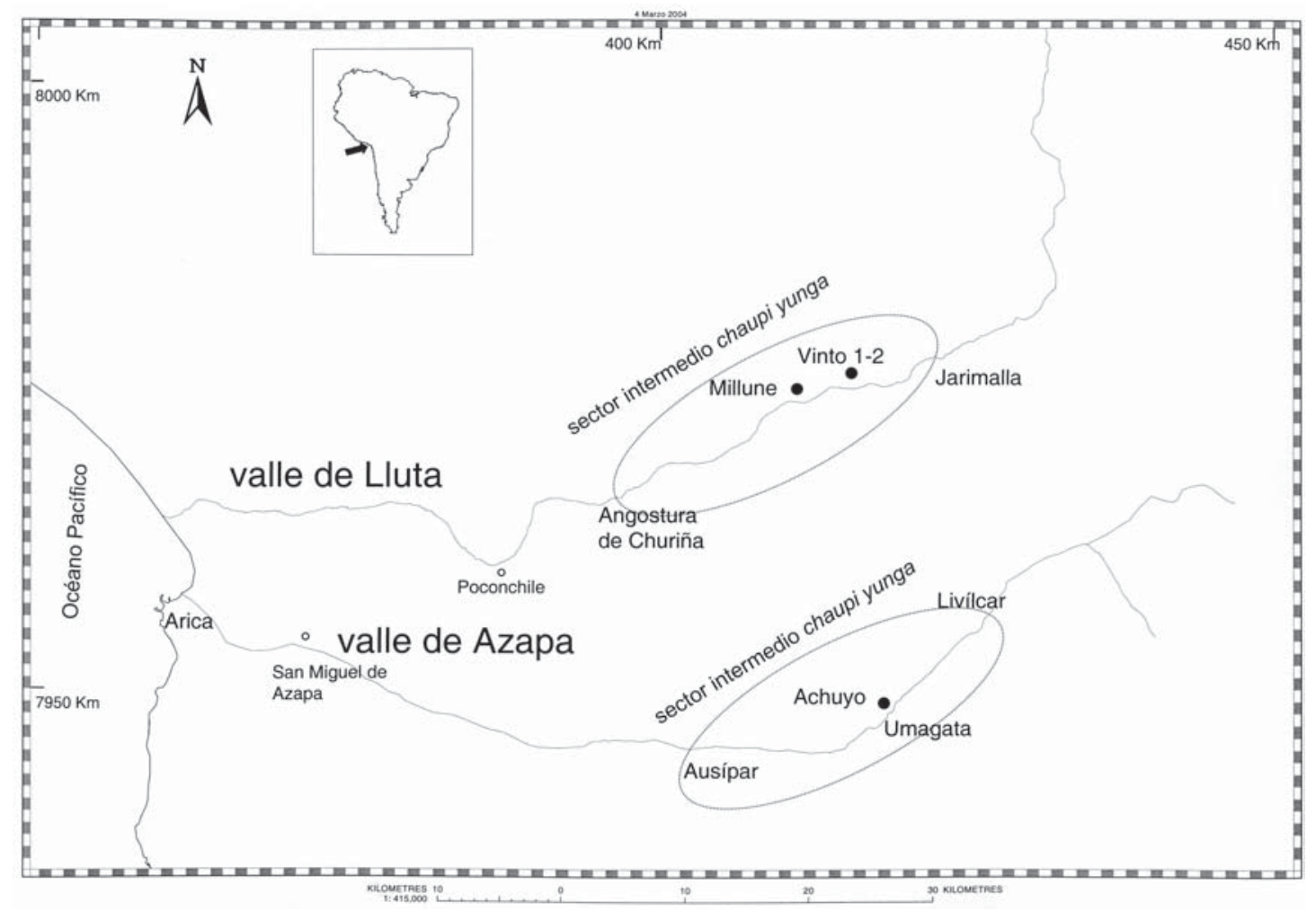

Figura 1. Localización de los sitios y sectores estudiados en los valles de Lluta y Azapa.

Location of the studied sites and sectors in the Lluta and Azapa valleys. 
bilidad de agua depende exclusivamente de lluvias generadas en la cordillera y vertientes de aguas subterráneas. Los espacios de ocupación prehispánica se restringen a pequeñas y estrechas terrazas ubicadas en forma discontinua a lo largo de estos valles, asociadas a vertientes de agua dulce.

El valle de Lluta nace en el altiplano y presenta un caudal permanente durante todo el año. Sin embargo, sus aguas son salobres con alto contenido de boro, lo que sumado a la mala calidad de los suelos han restringido el desarrollo de la agricultura hasta la actualidad. El valle de Azapa nace en la sierra y presenta un curso estacional y caudal más limitado; sin embargo, sus aguas y suelos son de mejor calidad para el desarrollo de la agricultura.

Nuestro estudio se centra en el sector ecológico que denominamos valle intermedio chaupi yunga (sensu Santoro et al. 2002), un ambiente preserrano que se ubica entre 950 y $1.800 \mathrm{~m}$ de altitud (entre 50 y $80 \mathrm{~km}$ de la costa). En el valle de Lluta, este sector abarca desde la angostura de Churiña hasta la localidad de Jarimalla; y en el valle de Azapa, el tramo comprendido entre las localidades de Ausípar y Livílcar (Figura 1). En este sector intermedio chaupi yunga, el valle es estrecho y el clima no recibe la influencia costera, por lo que es más cálido y seco, ideal para el cultivo de cocales y maíz. La ocupación se restringe a enclaves con suelos adecuados para agricultura con riego tecnificado, basado en canalización de vertientes, aguas del río y la preparación de eras de cultivo (Santoro et al. 2002).

\section{Análisis y Sitios}

Analizamos comparativamente tres sitios habitacionales ocupados al menos durante el período Tardío: Millune (Lluta-21) y Vinto 1-2 (Lluta92) en el valle de Lluta, y Achuyo (Az-58) en el valle de Azapa (Figura 1). Estos tres sitios corresponden a poblados con presencia de bloques con arte rupestre formando parte de los asentamientos.

Dado que sólo Millune ha sido excavado, la caracterización cronológico-cultural de los sitios se basó en el análisis de cerámica decorada, obtenida de recolecciones de superficie a través de muestreos al azar estratificados según los diferentes sectores funcionales de los asentamientos. En virtud de lo anterior, se considera que estos sitios fueron ocupados durante los períodos Intermedio Tardío (1.000-1.400 d.C.) y Tardío (1.400-1.530 d.C.), y presentan los siguientes componentes culturales:

Componente local de tierras bajas. Se caracteriza por los tipos cerámicos de la cultura Arica: San Miguel, Gentilar y Pocoma, correspondientes a la cerámica utilizada por los grupos locales que habitaron la costa y valles durante el período Intermedio Tardío (o Desarrollos Regionales) y período Tardío o Inka, con perduración hasta épocas coloniales tempranas (Romero 2002; Schiappacasse et al. 1989; Uribe 1999).

Componentes de tierras altas. Integrados por cerámica Charcollo (sensu Santoro et al. 2004), un tipo cerámico de origen serrano, y los tipos Negro sobre Rojo de origen altiplánico (genéricamente denominado Chilpe en los Valles Occidentales, Schiappacasse et al. 1989). Corresponden a la cerámica utilizada por las poblaciones de sierra y altiplano, durante el período Intermedio Tardío, prolongándose durante el período Tardío.

Componente Inka. Representado por los tipos cerámicos Saxamar (o Inka-Pacajes), Inka Policromo e Inka Bicromo (Romero 2002; Schaedel 1957). Estos tipos, considerados Inka provinciales, se vinculan al lapso de la expansión del Tawantinsuyu, donde posiblemente funcionaron como parte de los bienes de redistribución de estado. Estos tipos sirven de base para diagnosticar la relación y contemporaneidad con el Inka en los asentamientos estudiados.

Nuestro análisis se fundamentó en la contextualización del arte rupestre, considerando las siguientes variables que fueron interrelacionadas y comparadas entre los sitios, con miras a identificar asociaciones significativas que eventualmente permitieran reconocer un posible arte rupestre Inka:

- Componentes cerámicos de los asentamientos

- Características arquitectónicas y organización espacial de los poblados

- Condiciones de emplazamiento del arte rupestre

- Características formales del arte rupestre 


\section{Asentamientos y Arte Rupestre}

\section{Millune (Lluta-21)}

Se localiza en el valle de Lluta a $65 \mathrm{~km}$ de la costa (Figura 1), emplazado en el borde de una terraza alta, 10 a $15 \mathrm{~m}$ sobre el lecho del río, delimitada por profundas cárcavas que le dan una protección natural al asentamiento y buen dominio visual del valle. En el margen este de la terraza se encuentra la quebrada Millune regada por vertientes que mantienen una vegetación local. El sitio ha sido referido por Dauelsberg (1995 [1960]: 70-71), Mostny y Niemeyer (1983) y Schiappacasse et al. (1989).

Componentes cerámicos. Dada la mayoritaria presencia de cerámica de los tipos de la Cultura Arica $(52 \%)$, podemos señalar que Millune fue habitado principalmente por población local. Destaca además la presencia de componentes altiplánicos representados por cerámica Negro sobre Rojo (29\%). Presenta, en cambio, una baja incidencia de com- ponentes incaicos (6\% tipos Saxamar e Inka) y componentes de la sierra representados por cerámica Charcollo (5\%). Esta baja frecuencia de componentes incaicos puede dar cuenta de dos situaciones: que Millune fue ocupado con más intensidad durante el período Intermedio Tardío que en el Tardío; o que durante el Tardío no estuvo bien integrado a las redes de redistribución del estado. En ambas situaciones se verifica que Millune mantuvo vínculos estrechos con poblaciones de tierras altas, particularmente del altiplano, y posiblemente también con poblaciones serranas si consideramos que en todos los demás sitios de la zona baja del Lluta la cerámica Charcollo no alcanza más que $1 \%$ de presencia (Santoro et al. 2002).

Características arquitectónicas. Millune es un poblado de organización compleja, sin rasgos arquitectónicos incaicos, que presenta una sectorización denotada por diferencias arquitectónicas y de utilización del espacio: áreas habitacionales, de almacenaje comunitario, funerarias y públicas a modo de patios (Figura 2) (Santoro et al. 2002). Se

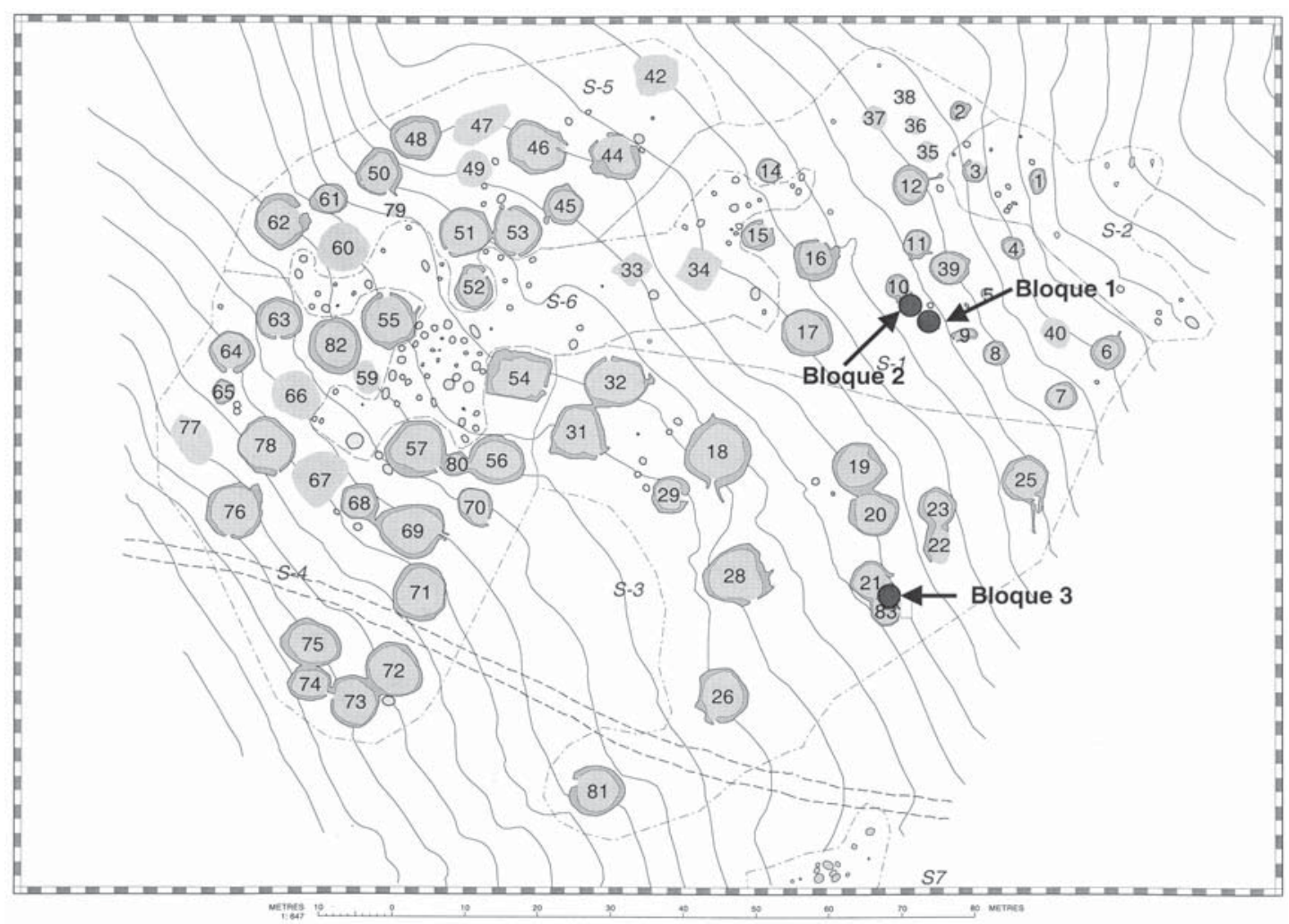

Figura 2: Distribución de las estructuras y bloques con arte rupestre en el poblado de Millune. Spatial distribution of the stone structures and blocks with rock art in Millune. 
compone de unos 80 recintos habitacionales de planta circular o semicircular socavada, de ca. $5 \mathrm{~m}$ de diámetro, con muros pircados sin argamasa, generalmente de doble hilada con relleno, de no más de $1 \mathrm{~m}$ de altura (Figura 3).

Las estructuras de almacenaje suman 140, la mayoría consisten en silos subterráneos de forma ampollar, con una apertura superior estrecha frecuentemente delimitada por piedras. Los silos se presentan al interior de recintos o adosados a ellos, o distribuidos en distintos sectores del poblado. Destaca un conjunto de 50 silos subterráneos agrupados en la parte central del poblado.

Segregadas espacialmente del ámbito doméstico, se distinguen cinco áreas funerarias separadas entre sí y diferenciadas arquitectónicamente, que incluyen cistas subterráneas, cistas aéreas y pircados simples.
Arte rupestre. El arte rupestre de Millune comprende tres pequeños bloques emplazados en el sector habitacional y distribuidos en un área de $100 \mathrm{~m}^{2}$ sin llegar a formar una agrupación concentrada. Los bloques aislados no forman parte de las estructuras, sino que se ubican en el exterior de los recintos (Figura 2).

Los tres bloques suman cuatro paneles grabados, ubicados principalmente sobre las caras superiores de los bloques. Todos los paneles presentan motivos abstractos, correspondientes invariablemente a horadaciones circulares u ovoidales que se disponen aisladas o en conjuntos, a veces unidas a líneas serpenteantes (Figura 4). Este diseño corresponde a la variante simple del "patrón abstracto de horadaciones y líneas" que se describe más adelante. No se registraron motivos figurativos en este poblado.

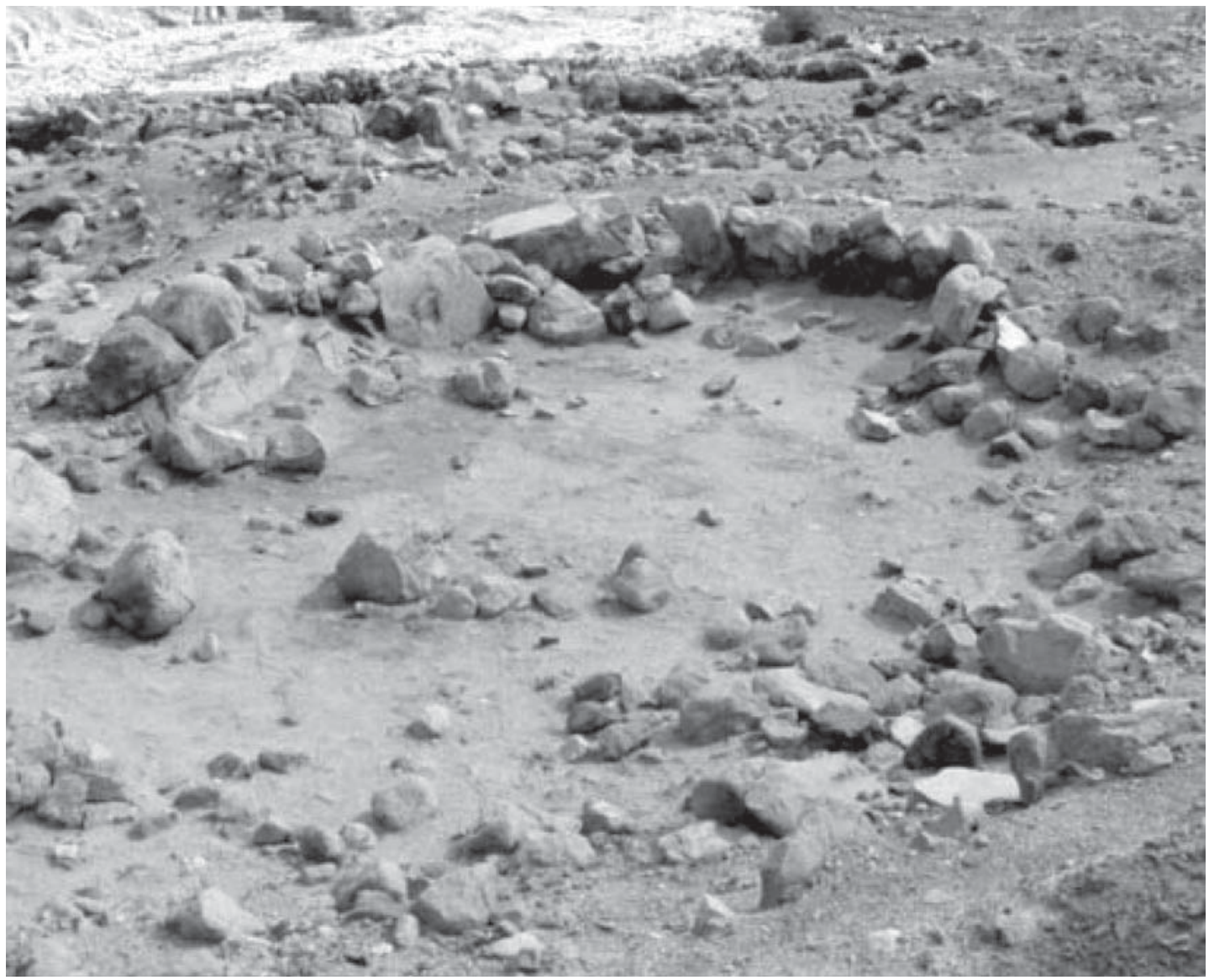

Figura 3. Detalle de la arquitectura de las unidades habitacionales de planta circular socavada de Millune (Fotografía Luz Andrea Pfister).

Architectural detail of semisubterranean circular domestic unit at Millune (Photo by Luz Andrea Pfister). 


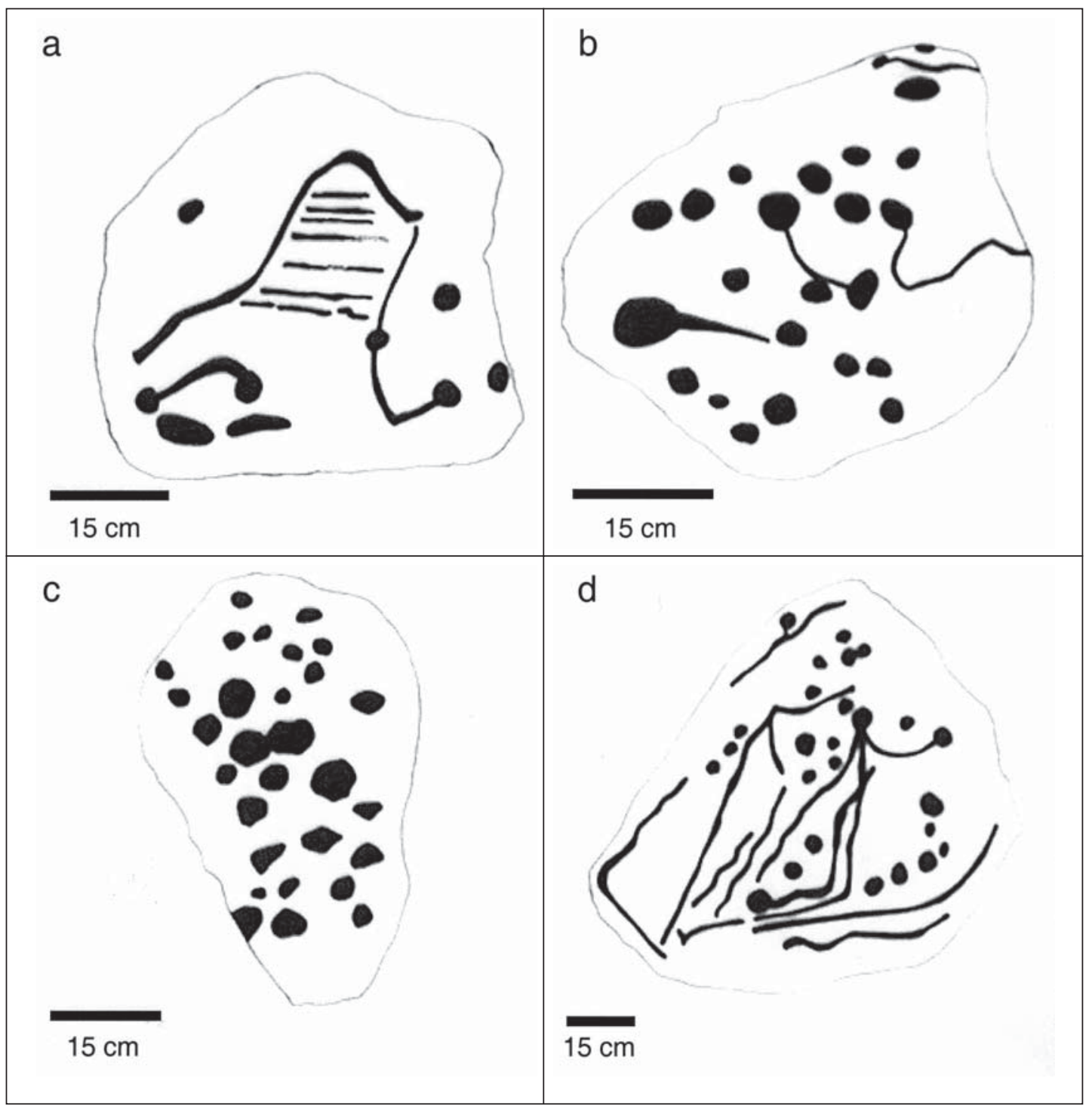

Figura 4. Arte rupestre de Millune. Variante simple del "patrón abstracto de horadaciones y líneas": (a) grabados sobre cara superior, bloque 2/I; (b) grabados sobre cara lateral, bloque 2/II; (c) grabados sobre cara superior, bloque 3/I; (d) grabados sobre cara superior, bloque $1 / \mathrm{I}$.

Rock art of Millune. Simple variant of the "abstract pattern with holes and lines": (a) ingraving over the top face, block 2/I; (b) ingraving on lateral face, block 2/II; (c) ingraving over the top face, block 3/I; (d) engraving over top face, block 1/I.

\section{Achuyo (Az-58)}

Se ubica en el valle de Azapa a unos $80 \mathrm{~km}$ de la costa (Figura 1). Se emplaza en una terraza elevada a más de $50 \mathrm{~m}$ sobre la caja del río, delimitada por barrancos abruptos, lo que otorga pleno dominio visual del sector comprendido entre Umagata y Molino. Este sitio fue inventariado por Dauelsberg (1995 [1959]: 41).
Componentes cerámicos. Este poblado, al igual que Millune, presenta un fuerte predominio de componentes Arica $(61,5 \%)$ y en menor medida componentes de la sierra y altiplano (cerámica Charcollo 12,8\%; Negro sobre Rojo 13,7\%). En tanto, existe una baja presencia de cerámica Inka (6\%, tipos Saxamar, Inka Policromo, Engobe Rojo). Al igual que Millune, a partir de las evidencias superficiales no se puede determinar con certeza la densidad 
ocupacional del período Tardío. Con todo, se puede considerar que Achuyo, de filiación local, interactuaba con poblaciones de tierras altas y posiblemente no estuvo bien integrado a las redes del estado Inka.

Características arquitectónicas. Al igual que Millune, Achuyo es un poblado de organización compleja, sin rasgos arquitectónicos incaicos, con sectores habitacionales, de almacenaje comunitario y un pequeño espacio público (Figura 5). El conjunto habitacional se compone de más de 80 recintos de planta circular socavada de ca. $6 \mathrm{~m}$ de diámetro y muros pircados de hilada doble con relleno. Incluye silos subterráneos distribuidos entre las unidades habitacionales y destaca una concentración de depósitos en un área central del poblado. En la pared norte del valle se registró un sistema de varios niveles de andenes de aproximadamente $150 \mathrm{~cm}$ de ancho y $50 \mathrm{~cm}$ de alto, de funcionalidad desconocida.

Arte rupestre. Comprende 24 bloques distribuidos dispersamente en el área habitacional, la mayoría fuera de los recintos habitacionales, pero hay algunos que forman parte de los muros de las estruc- turas. Este conjunto de arte rupestre es de mayor envergadura que los de los sitios de Lluta, en términos de cantidad y tamaño de los bloques.

La mayoría del arte rupestre (67\% de los bloques) corresponde a grabados de motivos abstractos de lineaturas serpenteantes con bifurcaciones sucesivas, unidas a horadaciones circulares u ovoidales, correspondientes a la variante simple del patrón abstracto (Figuras 6-7a). Estos rasgos se presentan con diferentes grados de complejidad y elaboración, y ocupan frecuentemente superficies convexas de las rocas. Una composición recurrente son líneas sinuosas grabadas, que descienden verticalmente desde la cima de la roca, por todos sus lados. El uso de superficies convexas en desmedro de superficies planas parece ser una decisión ex profeso por los artífices con el objeto de lograr un particular efecto tridimensional.

Se encontraron dos bloques (8\%) que presentan, junto con estos motivos abstractos, diseños figurativos de camélidos esquemáticos de cuatro patas de trazos gruesos (Figura 7b). Asimismo, una porción de bloques (25\%) presenta solamente grabados de cuadrúpedos esquemáticos del mismo tipo anterior, careciendo de motivos abstractos.

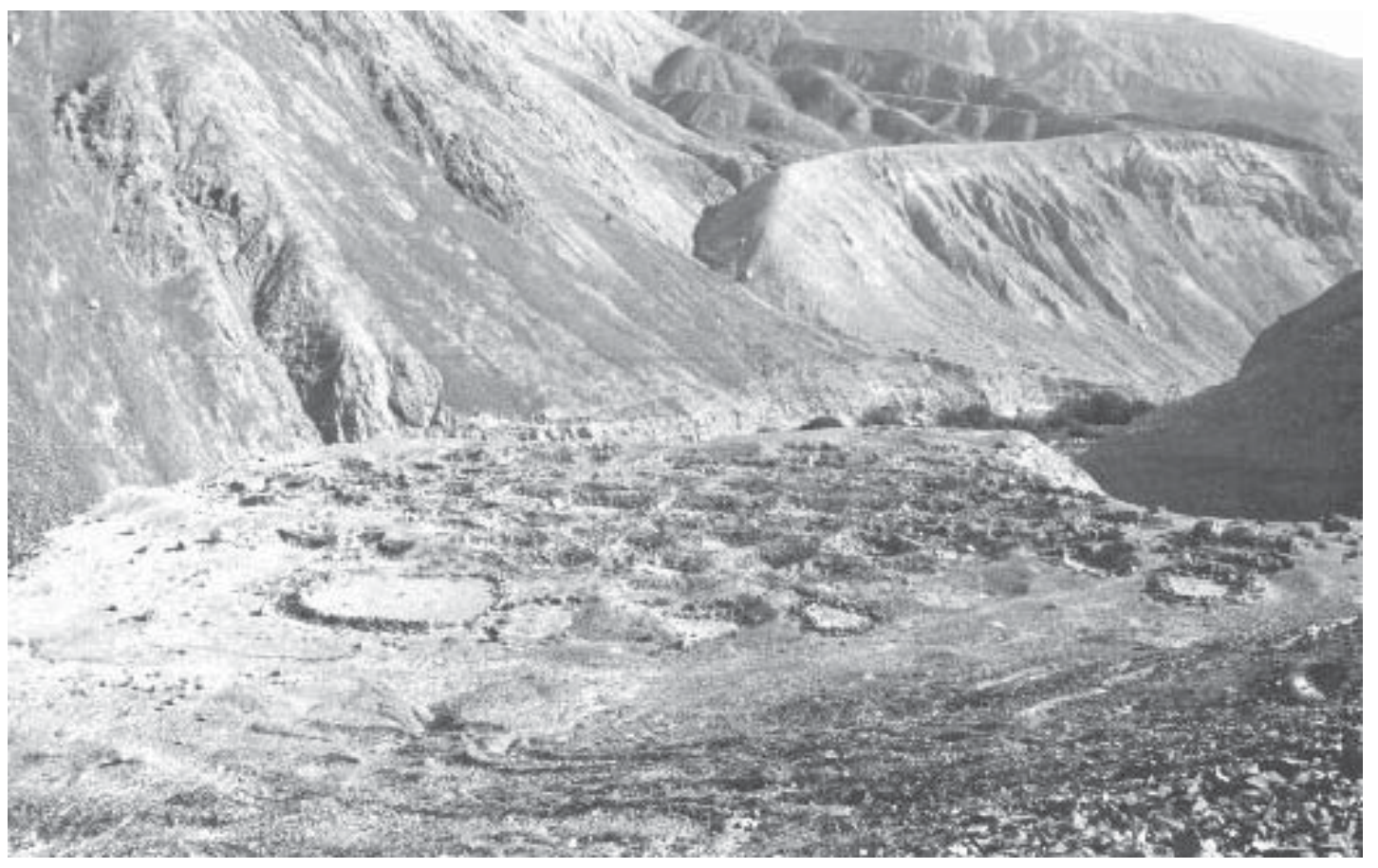

Figura 5. Vista general del poblado de Achuyo.

General view of Achuyo. 


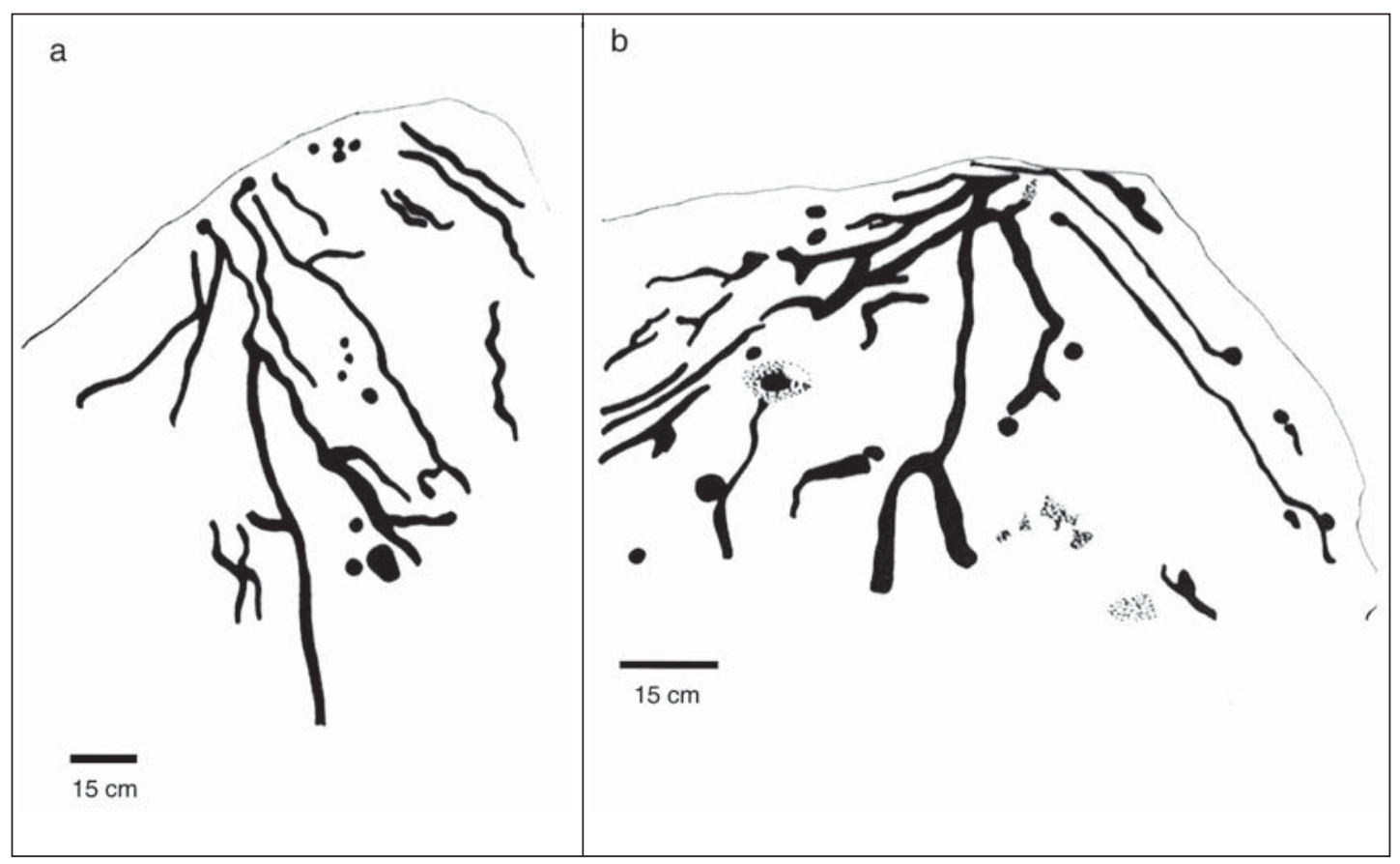

Figura 6. Arte rupestre de Achuyo, variante simple del patrón abstracto de horadaciones y líneas: (a) panel sobre superficie lateral convexa de la roca, sector NW del bloque 19; (b) panel sobre cara lateral convexa de bloque 12.

Rock art of Achuyo, simple variant of the abstract pattern with holes and lines: (a) panel over a convex lateral surface, sector $N W$ of block 19; (b) panel over convex lateral surface of block 12.

\section{Vinto 1-2 (Lluta-92)}

Corresponde a un asentamiento habitacional prehispánico ubicado en el valle de Lluta, a $74 \mathrm{~km}$ de la costa (Figura 1). Se emplaza en una explanada levantada $5 \mathrm{~m}$ sobre una terraza fluvial de uso agrícola, en un sector de ensanchamiento del valle. Estas condiciones, sumadas a la existencia de vertientes de agua dulce, convierten a esta localidad en un enclave doméstico y de buenas potencialidades agrícolas. Por su posición en altura, se tiene desde este sitio una muy buena visibilidad hacia el valle.

Componentes cerámicos. Podemos sostener que Vinto, a diferencia de Millune y Achuyo, presenta una fuerte vinculación con el Inka, en la medida que la cerámica Inka y Saxamar son mayoritarias. En efecto, los tipos incaicos en conjunto alcanzan el $47 \%$ de la cerámica decorada, dentro de los cuales el 28\% corresponden a tipos Inka Policromo y Bicromo y el $19 \%$ a Saxamar. A esto se agrega la alta incidencia del estilo altiplánico Negro sobre Rojo (32\%). En cambio, es notable la baja frecuen- cia de cerámica local Arica (6\%), un rasgo inusual en los poblados de tierras bajas. Esto sugiere que este asentamiento, posiblemente de origen altiplánico, estaba más integrado a la esfera del estado Inka.

Características arquitectónicas. Vinto es un pequeño asentamiento sin rasgos arquitectónicos incai$\cos$, compuesto por un área habitacional, un área funeraria, un espacio público tipo kancha y un área con arte rupestre que incluye nueve bloques grabados (Figura 8). El patrón de asentamiento es más bien disperso y no se adscribe al patrón arquitectónico de los sitios de Millune y Achuyo, puesto que presenta menor densidad de recintos y rasgos constructivos más simples, lo que denota menor planificación del asentamiento y tal vez una historia ocupacional más breve.

En el área habitacional, extremadamente erosionada como consecuencia de derrubios aluvionales, los recintos son de planta circular no socavados, de tamaños pequeños (ca. 2 a $3 \mathrm{~m}$ de diámetro) y delimitados por alineaciones o pircados simples de piedras. El área funeraria, ubicada 


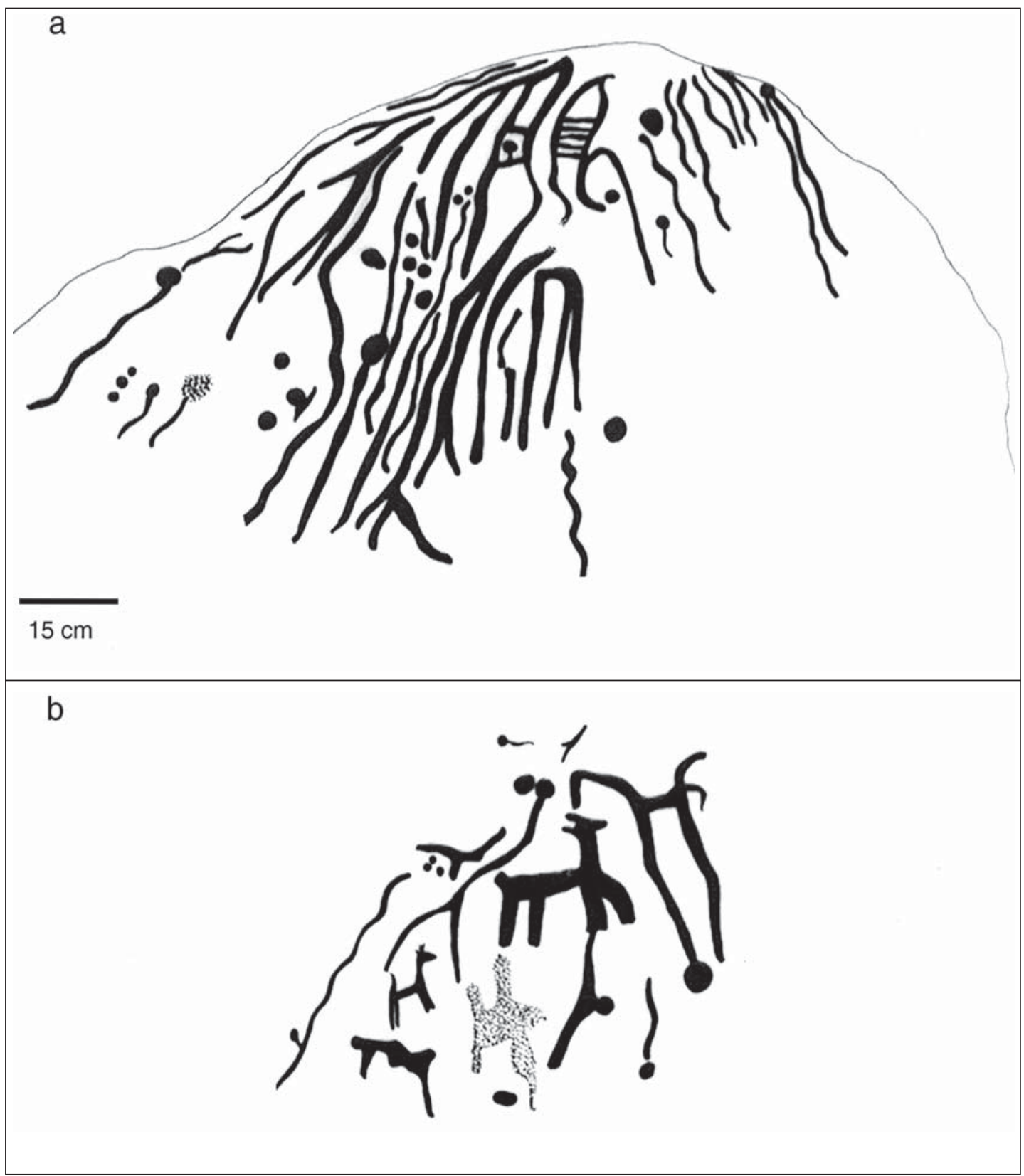

Figura 7. Arte rupestre de Achuyo: (a) variante simple del patrón abstracto, sobre superficie lateral convexa del bloque 21, roca grabada por todos sus contornos; (b) variante simple del patrón abstracto y camélidos esquemáticos, grabados sobre cara lateral del bloque 21.

Rock art of Achuyo: (a) simple variant of the abstract pattern over lateral convex surface block 21, rock engraved in all its faces; (b) simple variant of the abstract pattern and esquematic camelids, engraved over lateral face block 21.

en la parte alta de la explanada, comprende pequeñas cistas subterráneas cuadrangulares y circulares, formadas con lajas dispuestas verticalmente y/o adosadas a afloramientos rocosos. Destaca la presencia de un espacio sin delimitación formal, aplanado y despejado de ca. $250 \mathrm{~m}^{2}$, ubicado al oeste del área residencial, que definimos como kancha, de probable uso público.

Los bloques con arte rupestre se concentran en el sector oeste del poblado, aledaños a la kan- 


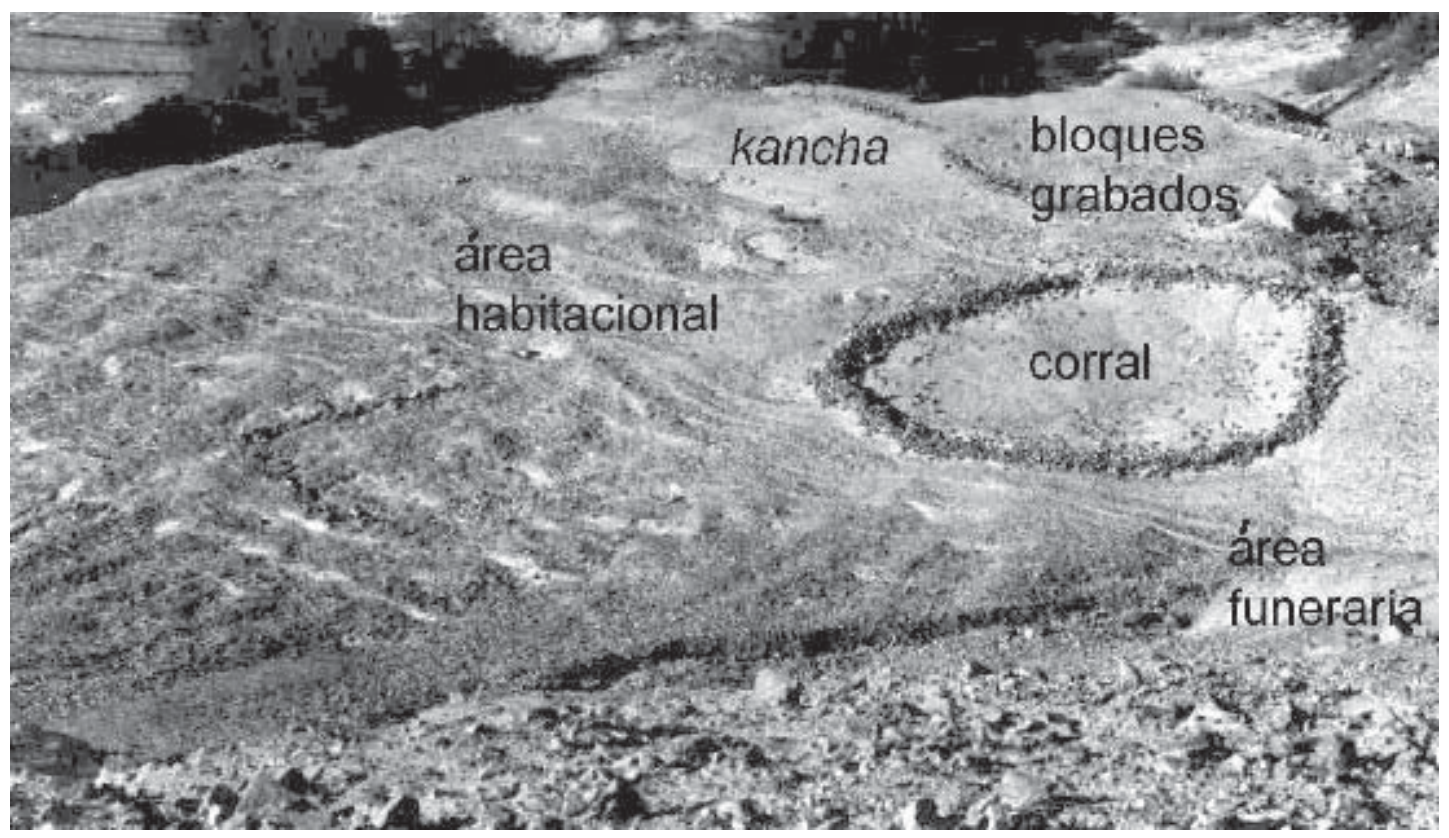

Figura 8. Vista general de Vinto 1-2: área habitacional de recintos circulares de pircado simple, kancha, área de bloques grabados, área funeraria y corral de posible origen prehispánico.

General view of Vinto 1-2: habitational area with circular structure of simple mamposterie, kancha area with engraved blocks, funerary area and corral of possible prehispanic origin.

cha. Bordea este sector un muro de piedras discontinuo de ca. $57 \mathrm{~m}$ de largo, de hilada simple sin argamasa, que incluye grabados formando parte del paramento.

Arte rupestre. El arte rupestre de Vinto comprende 13 paneles distribuidos en nueve bloques. La mayoría de los bloques (6) se concentran en el sector oeste aledaños a la kancha, uno de ellos formando parte del muro exterior del sitio (Figura 9). Otros tres bloques se localizan en el área habitacional del sector este del asentamiento.

Todos los paneles son grabados que abarcan las caras superiores de los bloques. Los motivos incluyen invariablemente motivos abstractos consistentes en líneas sinuosas asociadas a horadaciones circulares u ovoidales. Cinco paneles (38\%) presentan sólo horadaciones y/o líneas serpenteantes (variante simple). Seis paneles (47\%) incluyen, además, un motivo resultante de la configuración de los elementos anteriores, que denominamos variante compuesta: campos cuadrangulares formados por líneas serpenteantes y/o rectilíneas dispuestas paralela y perpendicularmente, o bien, por una línea a cuyos lados se disponen paralelamente ho- radaciones en hileras (Figuras 10-11). Esta configuración, que no aparece representada en los sitios Millune y Achuyo, la asimilamos a lo que Briones et al. (1999) denominan "motivo chacra", en virtud de su analogía a actuales "miniaturas de campos de cultivo" representadas por la disposición de piedras sobre el suelo. Los dos paneles restantes presentan motivos indeterminados debido a su mala conservación. No se registraron motivos figurativos.

\section{Síntesis y Discusión}

El arte rupestre de los sitios descritos es, en sus rasgos básicos, similar. Se trata de un arte esencialmente abstracto, consistente en un patrón formal que denominamos, con fines operativos para la exposición de este trabajo, "patrón abstracto de horadaciones y líneas". Éste se caracteriza por la combinación variable de horadaciones circulares u ovoidales y líneas sinuosas o serpenteantes que presentan a veces bifurcaciones. Las horadaciones son generalmente de tamaños pequeños (ca. 1-4 $\mathrm{cm}$ de diámetro y $1-3 \mathrm{~cm}$ de profundidad) y las líneas sinuosas o serpenteantes de surco profundo $(2-3 \mathrm{~cm})$, y se disponen generalmente sobre 


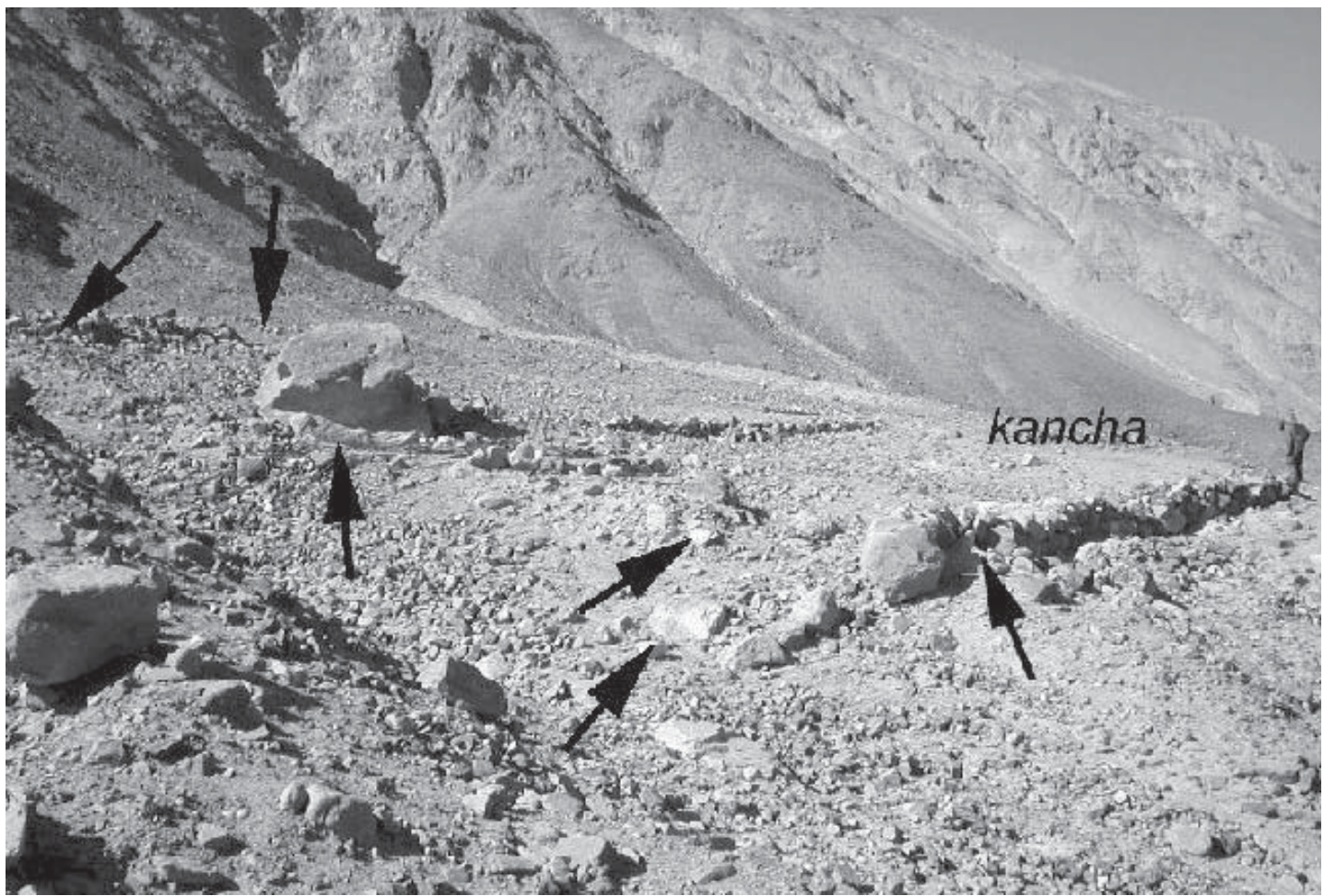

Figura 9. Ubicación de los bloques con arte rupestre (indicadas con flecha) en el sector oeste de Vinto 1-2, aledaños a la cancha. Location of blocks with rocks art (arrows) western sector of Vinto 1-2, next to the cancha.

paneles horizontales ubicados en las caras superiores de los bloques. Este patrón de arte rupestre tiene una especial representación en contextos habitacionales del valle de Lluta (Valenzuela 2004). Distinguimos dos variantes en este patrón: (a) una variante simple, en la que las horadaciones y líneas se disponen variablemente sin formar motivos definidos (Figuras 4, 6-7); y (b) una variante compuesta, consistente en campos cuadrangulares formados por la disposición paralela y perpendicular de líneas y/o horadaciones circulares u ovoidales (Figuras 10-11). Esta variante, a diferencia de la anterior, forma a partir de las horadaciones y líneas un motivo regular y más estandarizado, el "motivo chacra", que se repite sin grandes variaciones en diferentes soportes (geoglifos y petroglifos) en los Valles Occidentales. Este motivo se interpreta, sobre la base de información etnográfica, como representaciones de cochas, acequias y campos de cultivo, a modo de imágenes votivas para la fertilidad de la tierra y producción agrícola (Briones et al. 1999).

Basados en la contextualización del arte rupestre con respecto a su emplazamiento y caracte- rísticas formales, así como a los rasgos arquitectónicos y componentes culturales de los sitios, reconocemos una serie de diferencias y relaciones significativas que arrojan luz en la identificación de un posible arte rupestre Inka.

Por un lado, los sitios Millune y Achuyo presentan similitudes en el patrón arquitectónico y componentes culturales: ambos corresponden a poblados de organización compleja con similares características arquitectónicas, sin rasgos constructivos incaicos, de fuerte tradición local (Arica) que mantienen estrechas relaciones con poblaciones de tierras altas y escasa vinculación con las redes de interacción incaicas. El arte rupestre corresponde a motivos abstractos de la variante simple del "patrón abstracto de horadaciones y líneas" donde los elementos horadaciones y líneas se combinan variablemente sin formar motivos definidos. Los bloques grabados se emplazan dispersos entre los recintos habitacionales.

Por otro lado, Vinto corresponde a un poblado de patrón arquitectónico diferente, menos planificado, con estructuras de construcción más simple y menor sectorización funcional. No presenta 
a

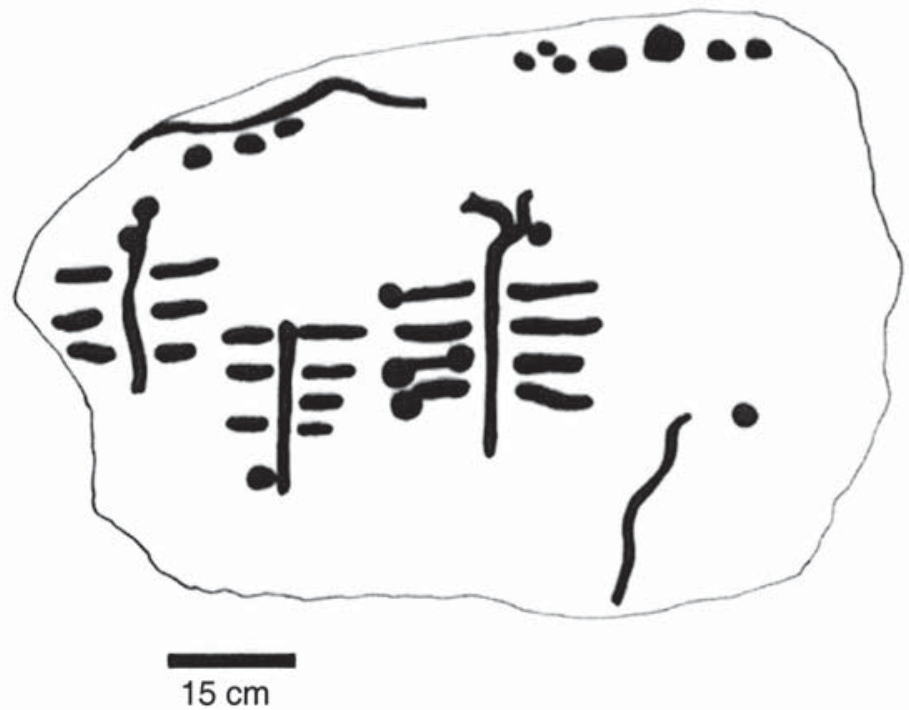

b

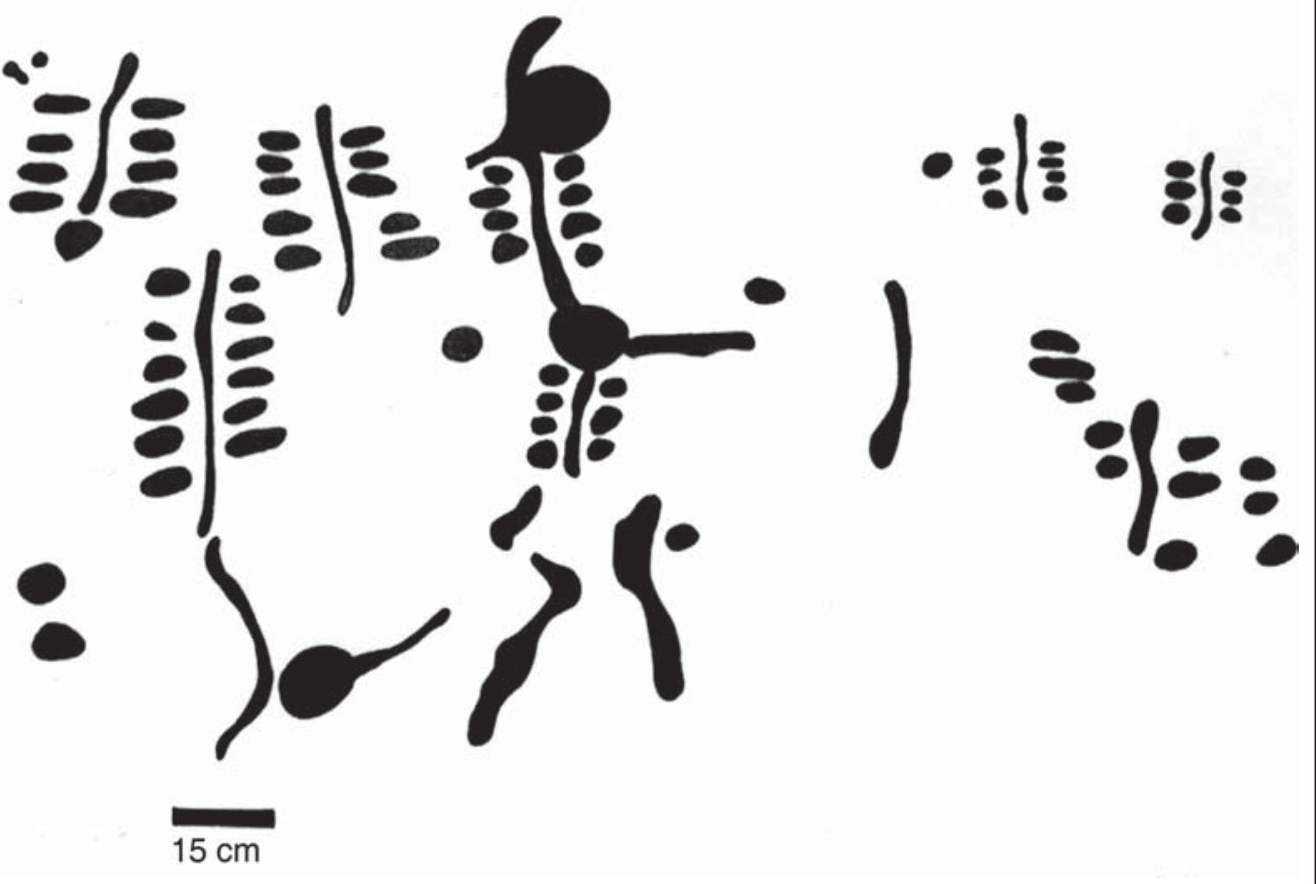

Figura 10. Arte rupestre de Vinto 1-2: (a) panel en cara superior del bloque C2-3 con variante simple y compuesta; en el sector superior y esquina inferior derecha de la figura, se observa la variante compuesta del patrón abstracto; (b) variante compuesta en cara superior del bloque C1-4; en el sector inferior de la figura, se observan ejemplos de la variante simple.

Rock art Vinto 1-2: (a) panel over superior face block C2-3 with simple and composed variants; the upper sector and lower right corner of the figure show the composed variant of the abstract pattern; (b) composed variant over the superior face block C1-4; the lower section of the figure show examples of the simple variant. 


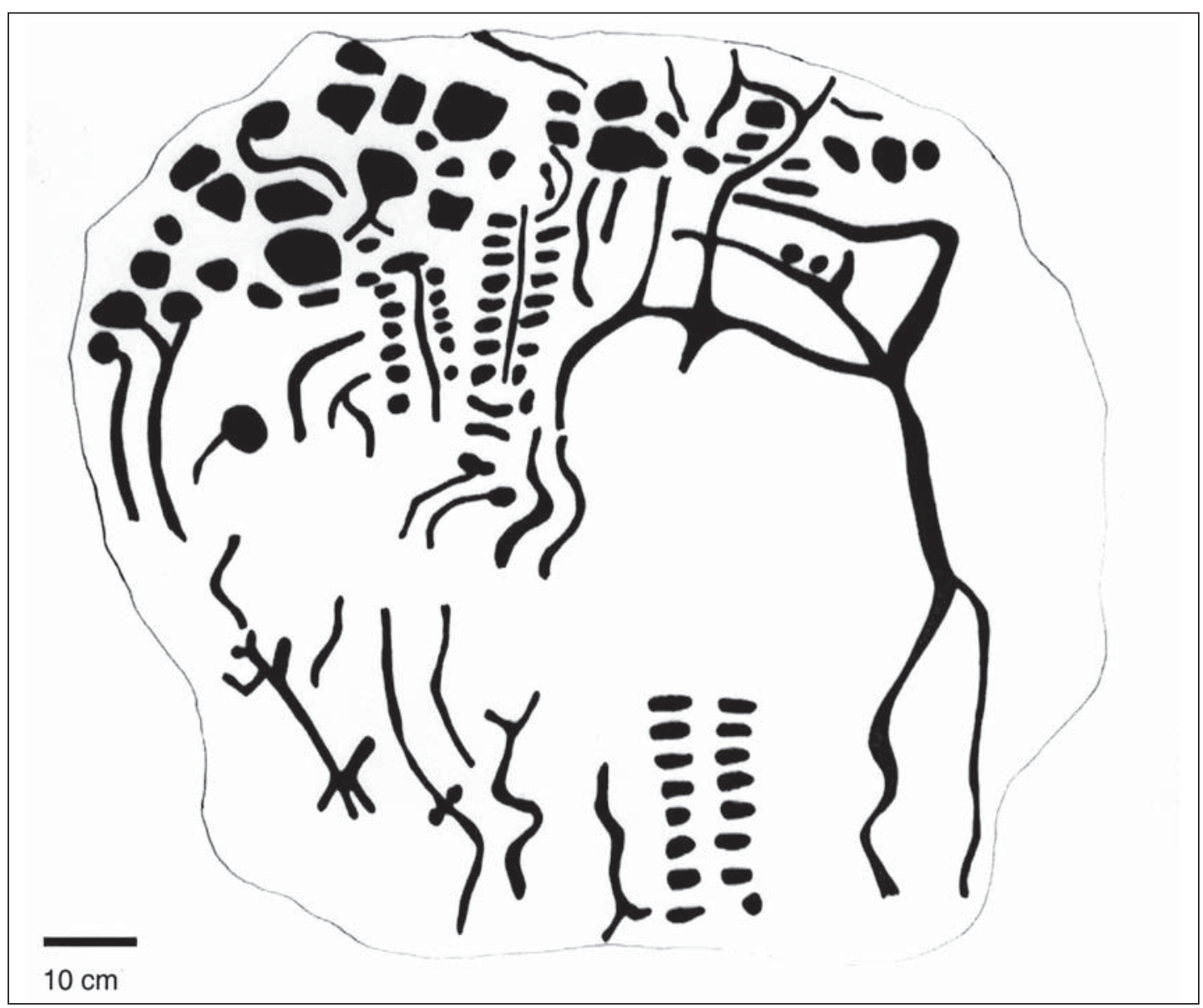

Figura 11. Arte rupestre de Vinto 1-2: variante simple y compuesta en cara superior del bloque C1-3.

Rock art of Vinto 1-2: simple variant and complex variant over superior face block C1-3.

arquitectura incaica, pero los componentes cerámicos sugieren un origen altiplánico estrechamente vinculado a las redes de interacción del Tawantinsuyu. El arte rupestre de Vinto también difiere de los sitios Millune y Achuyo puesto que incluye, además de la variante simple, la variante compuesta que forma, a partir de las horadaciones y líneas, un motivo estandarizado. La presencia exclusiva de esta variante en Vinto, junto a la alta incidencia de cerámica de filiación Inka y la disposición concentrada del arte rupestre en un espacio público (kancha), dan cuenta de una situación diferente.

Estas similitudes y diferencias entre los sitios nos permiten postular, a modo de hipótesis, que el arte rupestre de Vinto podría estar vinculado al estado Inka. Los rasgos representacionales de la va- riante compuesta o "motivo chacra" nos sugieren cierta similitud, en términos conceptuales o iconográficos, con las denominadas "maquetas" del Río Salado (Loa Superior), caracterizadas por pronunciados bajorrelieves que representan campos de cultivo y sistemas de regadío, y son adscritos al período Inka en virtud de su asimilación a afloramientos rocosos esculpidos incaicos, considerados parte de la arquitectura de asentamientos Inka, como los ejemplos de Kenko en Cuzco, Samaipata y Copacabana en Bolivia (Gallardo et al. 1999; Hyslop 1990; Vilches y Uribe 1999; Van de Guchte 1999; Vilches 1999). La misma conexión sugiere Podestá para las "maquetas" de Antofagasta de la Sierra en el Noroeste Argentino (Podestá 1997). Otras referencias provenientes de Argentina y Bolivia advierten la presencia del "patrón abstracto 
de horadaciones y líneas" relacionado con sectores agrícolas o fuentes de agua, y lo vinculan al estado Inka. Por ejemplo, Hernández Llosas (2003) sugiere que motivos como serpentiformes y "morteritos" (horadaciones) de la quebrada de Humahuaca (Noroeste Argentino), en determinados contextos, tales como en asociación a recursos de agua y al camino Inka, podrían corresponder al momento de ocupación Inka en la zona. En el altiplano boliviano, Meddens (2003) ha constatado la presencia de similares motivos en bloques asociados a sitios incaicos del valle Chicha, en el territorio Soras, postulando una conexión entre las piedras grabadas, la organización del paisaje, el manejo local de los ciclos agrícolas y la administración Inka de la producción.

Sugerimos que el "patrón abstracto de horadaciones y líneas" se deslinda como una manifestación local pre Inka, expresada en la variante simple, bien representada en Achuyo y Millune, y en menor medida en Vinto. Sostenemos que la variante simple tiene raíces locales no sólo por su presencia en los sitios aquí estudiados con componentes predominantemente locales, sino también por su relativamente amplia distribución en sitios de filiación pre Inka en diversas zonas de los Valles Occidentales (Gordillo 1992; Linares Málaga 1968; Niemeyer 1968-69; Niemeyer y Schiappacasse 1963). Con el Inka este patrón es tomado, reacomodado según los cánones estilísticos incaicos y transformado en un motivo mucho más estandarizado, "chacras" cuadrangulares, que aparece recurrentemente bajo las mismas características formales en distintos sitios de los Valles Occidentales. Adicionalmente, el Inka le confirió un carácter distinto en la medida que los bloques grabados, si bien en ambos casos se insertaban en un espacio netamente habitacional (dentro del asentamiento), con el Inka se trasladan, dentro del ámbito habitacional, a un espacio de uso público. Otros investigadores han remarcado la importancia de la apropiación y transformación que hace el Inka de elementos locales dentro de los principios imperiales como una forma de legitimar su poder (Cornejo 1995; Gallardo et al. 1995; Uribe y Adán 1999; Uribe et al. 2000), lo que se expresa, en este caso, en la transformación de la variante simple-local en la variante compuesta-incaica y en el traslado del arte rupestre desde un ámbito más privado a un espacio público, ahora modificado según principios incaicos y para fines estatales.

Con relación al rol del arte rupestre en el proceso de integración de las poblaciones de esta zona al estado Inka, podemos concluir lo siguiente de acuerdo a nuestras preguntas de investigación. Considerando al Tawantinsuyu como una entidad política dinámica que empleó distintas estrategias de expansión (Castro 1992; D’Altroy 1992; Hyslop 1990; Niles 1993; Pease 1979; Uribe y Adán 1999, 2004), los sitios analizados formarían parte de un contexto particular de influencia incaica, que parece ser común a los valles bajos y costa de Arica. Se trata de sitios de origen local, sin rasgos arquitectónicos incaicos, que presentan material mueble de filiación incaica, como la cerámica. Distinta es la situación en la sierra y altiplano de la zona, o en las tierras altas de la II Región de Chile, donde la presencia del estado Inka es más "visible". Esto se evidencia en instalaciones de clara planificación y construcción Inka que sirvieron al funcionamiento del estado, como, por ejemplo, el tambo y las colcas de Zapahuira en la sierra de Arica (Muñoz y Chacama 1993); o a través de asentamientos de origen local con rasgos arquitectónicos incaicos que irrumpen en la instalación urbanística previa, como Saguara 2, en los altos de Camarones (Schiappacasse y Niemeyer 2002), o el Pukara de Turi en el río Loa (Castro y Cornejo 1990; Castro et al. 1993).

Los sitios Millune y Achuyo presentados en este trabajo corresponden a instalaciones locales de tradición cultural de tierras bajas o Arica, que durante el período Tardío presentan una leve intrusión de rasgos muebles típicamente incaicos, como la cerámica Saxamar e Inka. Además, ambos presentan la variante simple del patrón de arte rupestre abstracto, restringido a un ámbito privado puesto que los bloques se ubican dispersamente entre las unidades domésticas.

El sitio Vinto, en cambio, exhibe rasgos y características que demuestran una mayor articulación con el estado, aún cuando no presenta arquitectura incaica: muestra una muy alta incidencia de cerámica de filiación Inka en desmedro de lo local; el arte rupestre incluye la variante compuesta que puede considerarse de filiación Inka; y el arte rupestre se despliega en un espacio público (kancha). Vinto podría corresponder a un sitio ha- 
bitacional de probable origen altiplánico que se instaló con fines de explotación agrícola, aprovechando las terrazas fluviales y las vertientes que brinda el sector. La cerámica incaica presente en el sitio sería consecuencia de parte del flujo de bienes de redistribución del estado y de estrategias de control ideológico.

Pensamos que la administración del estado en los valles bajos de los Valles Occidentales no se expresó en instalaciones administrativas visibles, lo que D'Altroy (1992) denomina "estrategias de control territorial". El uso de elementos de menor visibilidad arqueológica, como la cerámica y de corte más ideológico como el arte rupestre, indica una "estrategia de control hegemónico" en los términos del mismo autor, cuyos componentes comenzamos a dilucidar.

Esta administración, sin embargo, no fue tan "indirecta" como pensábamos hasta hace algunos años. Durante este período, el estado aplicó su sistema administrativo basado en la contabilidad de los quipus que aparecen en los registros arqueológicos de Arica y las comunidades locales enfrentaron una serie de cambios documentados en los patrones de asentamiento, uso de bienes de prestigio, incorporación de nuevas tareas productivas y cambios en la dieta que además afectaron las condiciones de salud (Romero 2002; Santoro 1995; Santoro et al. 2002; 2003).

En este contexto, sugerimos, a modo de hipótesis, que la variante compuesta o "motivo chacra" podría haber constituido uno de los elementos representativos de la expansión y administración estatal Inka hacia los Andes Centro Sur. Esto en virtud de su analogía con las denominadas maquetas del Loa Superior (Gallardo et al. 1999; Vilches y Uribe 1999) y motivos similares en el Noroeste Argentino (Podestá 1997; Hernández Llosas 2003) y altiplano de Bolivia (Meddens 2003). No obstante, la identificación y contextualización de este motivo en otras partes de los Andes Centro Sur es imprescindible para apoyar esta hipótesis, puesto que si bien conocemos varios sitios en los Valles Occidentales donde se presenta la variante compuesta (Luis Briones comunicación personal 2003), éstos requieren de contextualización cultural para sostener una posible vinculación con el estado Inka. Por el momento, nuestro trabajo aporta con una línea de evidencia contextual que permite asociar la variante compuesta al estado Inka para un sitio del valle de Lluta. Específicamente, el uso de un arte rupestre estandarizado por el estado pero de raíces locales pudo servir como un instrumento ideológico de control para el funcionamiento del sistema sin uso de fuerza militar. Es interesante notar que estos motivos se desplegaban en espacios públicos, como kanchas, donde posiblemente se llevaban a cabo actividades políticas o rituales que sancionaban o ratificaban las obligaciones de la comunidad con el estado (mit'a agrícola en este caso), en el marco de los mecanismos de redistribución y reciprocidad asimétrica.

Este caso de estudio, aunque es una muestra a pequeña escala, ha permitido segregar componentes iconográficos con relación a componentes culturales específicos, contextualizando las representaciones del patrón abstracto de acuerdo a determinadas condiciones. En virtud de esto es que sugerimos la vinculación de la variante compuesta con el Inka. Deberemos, a futuro, ampliar los casos donde se manifieste esta variante y estudiar cómo se comporta el arte rupestre en relación con su contexto arqueológico-cultural.

En síntesis, los resultados de este estudio muestran que el estado también se manifestó en el nivel ideológico, incorporando una serie iconográfica expresada en el arte rupestre que, aunque pudo ser en algunos casos de origen local, fue transformada e integrada al sistema ideológico estatal. En los sitios estudiados, el cambio más notorio es el manejo del arte rupestre para la conformación de espacios públicos, inexistentes previamente.

Agradecimientos: Este trabajo es resultado de los proyectos Fondecyt № 1000457 y N 1030312 y del Centro de Investigaciones del Hombre en el Desierto (CIHDE). Agradecemos a Frank Meddens la gentileza de proporcionarnos su manuscrito inédito, a Ray Lefebvre y Ann Peters la corrección de los textos en inglés. 


\section{Referencias Citadas}

Albarracín Jordán, J.

1991 Petroglifos en el Valle Bajo de Tiwanaku, Bolivia. Boletín de la SIARB 5:35-56.

Aschero, $\mathrm{C}$.

2000 Figuras humanas, camélidos y espacios en la interacción circumpuneña. En Arte en las Rocas. Arte Rupestre, Menhires y Piedras de Colores en Argentina, editado por M. Podestá y M. de Hoyos, pp. 15-44. Sociedad Argentina de Antropología y Asociación Amigos del INAPL, Buenos Aires.

Briones, L., P. Clarkson, A. Díaz y C. Mondaca

1999 Huasquiña, las chacras y los geoglifos del desierto: una aproximación al arte rupestre andino. Diálogo Andino 18:39-61.

Castro, V.

1992 Nuevos registros de la presencia Inka en la Provincia de El Loa, Chile. Gaceta Arqueológica Andina VI (21): 139-154.

Castro, V. y L. Cornejo

1990 Estudios en el Pukara de Turi. Gaceta Arqueológica Andina V(17):57-66.

Castro, V., F. Maldonado y M. Vásquez

1993 Arquitectura del 'Pukara' de Turi. En Actas del XII Congreso Nacional de Arqueología Chilena, Tomo II: 79-106. Boletín del Museo Regional de la Araucanía 4, Temuco.

Cornejo, L.

1995 El Inka en la región del Río Loa: lo local y lo foráneo. Actas del XIII Congreso Nacional de Arqueología Chilena, Tomo I:203-212. Hombre y Desierto 9, Antofagasta.

D'Altroy, T.

1992 Provincial Power in the Inka Empire. Smithsonian Institution Press, Washington \& London.

Dauelsberg, P.

1995 [1959] Contribución a la arqueología del valle de Azapa. Boletín Museo Regional de Arica 3:36-52. Reeditado por L. Álvarez.

1995 [1960] Reconocimiento arqueológico de los valles de Lluta, Vitor y la zona costera de Arica. Boletín del Museo Regional de Arica 4:70-77. Reeditado por L. Álvarez.

Fernández Distel, A.

1974 Petroglifos de Sapagua (Prov. de Jujuy, Argentina). Jujuy Cultural 1(1).

1976 Relaciones entre la estación rupestre de Angosto de Hornaditas (Jujuy, Argentina) y la alfarería arqueológica del área inmediata. Bollettino del Centro Camuno di Studi Preistorici XIII-XIV:167-178.

Gallardo, F. y F. Vilches

1995 Notas acerca de los estilos de arte rupestre en el pukara de Turi (norte de Chile). Boletín Sociedad Chilena de Arqueología 20:26-28.

Gallardo, F., C. Sinclaire y C. Silva

1999 Arte rupestre, emplazamiento y paisaje en la Cordillera del Desierto de Atacama. En Arte Rupestre en los Andes de Capricornio, editado por J. Berenguer y F. Gallardo, pp. 57-96. Museo Chileno de Arte Precolombino, Santiago.

Gallardo, F., M. Uribe y P. Ayala

1995 Arquitectura Inka y poder en el pukara de Turi, norte de Chile. Gaceta Arqueológica Andina 24:151-171.
Gordillo Begazo, J.

1992 Petroglifos y tráfico: un caso de interacción micro-regional en el ámbito de los valles de Tacna, Perú. Boletín de la SIARB 6:54-63.

Haffernan, K.J.

1996 The mitimaes of Tilka and the Inka incorporation of Chinchaysuyu. Tawantinsuyu 2:23-36.

Hernández Llosas, M.I.

2003 La presencia Inca y su posible correlación con sitios y motivos rupestres en la Quebrada de Humahuaca (Jujuy, Argentina). Ponencia presentada en el VI Simposio Internacional de Arte Rupestre, S.S. de Jujuy.

Hosting, R.

2002 Interrogantes sobre las piedras grabadas en templos coloniales del sur del Perú. Boletín de la SIARB 16:39-46.

Husson, J-Ph.

1998 El estado Neo-Inca de Vilcabamba, posible foco de las representaciones de la muerte de Atawuallpa. Tawantinsuyu 5:71-81.

Hyslop, J.

1990 Inka Settlement Planning. University of Texas Press, Austin.

Krapovickas, $\mathrm{P}$.

1961 Noticia sobre el arte rupestre de Yavi, Provincia de Jujuy, República Argentina. Anales de Arqueología y Etnología XVI:135-167.

Linares Málaga, E.

1968 El arte rupestre en el sur del Perú (departamentos Arequipa, Moquegua y Tacna). Actas y Memorias del XXXVII Congreso Internacional de Americanistas, Tomo II: 379-389. Buenos Aires.

Meddens, F.

2003 Rocks and stones in the landscape, managing the Inca agricultural cycle. Manuscrito en posesión del autor.

Meyers, A.

1998 Las campañas arqueológicas en Samaipata, 1994-1996. Segundo Informe de Trabajo. Boletín de la SIARB 12:5986.

Mostny, G. y H. Niemeyer

1983 Arte Rupestre Chileno. Serie Patrimonio Cultural Chileno, Ministerio de Educación, Santiago.

Muñoz, I. y J. Chacama

1993 El Inka en la Sierra de Arica. Actas del XII Congreso Nacional de Arqueología Chilena, Tomo I: 269-284. Boletín del Museo Regional de la Araucanía 4, Temuco.

Muñoz, I., J. Chacama y G. Espinosa

1987 El poblamiento prehispánico tardío en el valle de Codpa. Una aproximación a la historia regional. Chungara 19:7-61.

Niemeyer, $\mathrm{H}$.

1968-69 Los petroglifos de Taltape (Valle de Camarones, Prov. de Tarapacá). Boletín del Museo Nacional de Historia Natural XXX:95-117.

Niemeyer, H. y V. Schiappacasse

1963 Investigaciones arqueológicas en las terrazas de Conanoxa, valle de Camarones (Provincia de Tarapacá). Revista Universitaria 26:101-153.

Niles, $\mathrm{S}$.

1993 The provinces in the heartland: stylistic variation and architectural innovation near inca Cuzco. En Provincial 
Inca. Archaeological and Ethnohistorical Assessment of the Impact of the Inca State, editado por Michael A. Malpass, pp. 145-176, University of Iowa Press, Iowa City.

Núñez Jiménez, A.

1986 Petroglifos del Perú. Panorama mundial del arte rupestre. Volúmenes 3 y 4 . Editorial Científico-Técnica, La Habana.

Pease, F.

1979 La formación del Tawantinsuyu: mecanismos de colonización y relación con las unidades étnicas. Histórica III (1):97-120.

Podestá, M.M.

1997 Arte Rupestre Argentino: su Documentación y Preservación. Instituto Nacional de Antropología y Pensamiento Latinoamericano, Buenos Aires.

Romero, A.

2002 Cerámica doméstica del valle de Lluta: cultura local y redes de interacción Inka. Chungara Revista de Antropología Chilena 34:191-213.

Ruiz, M., M.E. Albeck y D. Charolque

2001 Conflicto y memoria. Arte rupestre de las tierras altas de Jujuy. Siglos XII al XV. En Arte Rupestre y Región. Arte Rupestre y Menhires en el Sur de Bolivia, NO de Argentina y Norte de Chile, compilado por A. Fernández Distel, pp. 8190. Centro de Estudios Indígenas y Coloniales, S.S. de Jujuy.

Santoro, C.

1995 Late Prehistoric Regional Interaction and Social Change in a Coastal of Northern Chile. Ph.D. Dissertation. University of Pittsburgh, Pittsburgh.

Santoro, C. e I. Muñoz

1981 Patrón habitacional incaico en el área de Pampa Alto Ramírez (Arica, Chile). Chungara 7:144-171.

Santoro, C., A. Romero y V. Standen

2002 Interacción social en los períodos Intermedio Tardío y Tardío, valle de Lluta, norte de Chile. En La Arqueología y la Etnohistoria en los Andes, editado por John Topic. Instituto de Estudios Peruanos, Lima. En Prensa.

Santoro, C., A. Romero, V. Standen y A. Torres.

2004 Continuidad y cambio en las comunidades locales, períodos Intermedio Tardío y Tardío, Valles Occidentales, área Centro Sur Andina. Actas del XV Congreso Nacional de Arqueología Chilena. Chungara Revista de Antropología Chilena Volumen Especial: 235-247.

Santoro, C., S. Dorsey-Vinton y K.J. Reinhard

2003 Inca expansion and parasitism in the Lluta valley: Preliminary data. Mem. Inst. Oswaldo Cruz 98(I):161-163.

Schaedel, R.

1957 Secuencias culturales de la zona de Arica (comparación de las secuencias de Uhle y Bird). En Arqueología Chilena: Contribuciones al Estudio de la Región Comprendida entre Arica y La Serena, editado por R. Schaedel, pp. 77-122. Centro de Estudios Antropológicos, Universidad de Chile, Santiago.

Schjellerup, I.

1998 Aspects of the Inca Frontier in the Cachapoyas. Tawantinsuyu 5:160-165.

Schiappacasse, V., V. Castro y H. Niemeyer

1989 Los Desarrollos Regionales en el Norte Grande (1.000 -1.400 d.C.). En Culturas de Chile. Prehistoria, editado por J. Hidalgo, V. Schiappacasse, H. Niemeyer, C. Aldunate e I. Solimano, pp. 181-220. Editorial Andrés Bello, Santiago.

Schiappacasse, V. y H. Niemeyer

2002 Ceremonial inca provincial: el asentamiento de Saguara (valle de Camarones). Chungara Revista de Antropología Chilena 34:53-84.

Schobinger, J.

2003 Noticia sobre el primer petroglifo incaico ubicado en la provincia de San Juan. Ponencia presentada en el VI Simposio Internacional de Arte Rupestre, S.S. de Jujuy.

Troncoso, A.

2003 Proposición de estilos para el arte rupestre del valle de Putaendo, curso superior del río Aconcagua. Chungara Revista de Antropología Chilena 35:209-231.

Uribe, M.

1998 [1913] Acerca de la interpretación de los intihuatanas. En Max Uhle y el Perú Antiguo, editado por P. Kaulicke, pp. 283-300. Fondo Editorial PUCP, Lima.

1999 La cerámica de Arica 40 años después de Dauelsberg. Chungara 31:189-228.

Uribe, M. y L. Adán

1999 Del Tawantinsuyu en las tierras altas del río Loa, Caspana, Norte Grande de Chile. Informe Interno Proyecto Fondecyt 1970528, Santiago.

2004 Acerca del dominio Inka, sin miedo, sin vergüenza. Actas del XV Congreso Nacional de Arqueología Chilena. Chungara Revista de Antropología Chilena Volumen Especial: 467-480.

Uribe, M.; V. Manríquez y L. Adán

2000 El 'Poder' del Inka en Chile: Aproximaciones a partir de la arqueología de Caspana (Río Loa, Desierto de Atacama). Actas del 3 er Congreso Chileno de Antropología, Tomo II: 706-722, Santiago.

Valenzuela, D.

2004 Imágenes sobre Piedra y Tierra: las Sociedades del Valle de Lluta, Períodos Intermedio Tardio y Tardio. Memoria para optar al título profesional de arqueóloga. Departamento de Antropología, Universidad de Chile, Santiago.

Van de Guchte, M.

1984 El ciclo mítico de la Piedra Cansada. Revista Andina 4(2):539-556.

1999 The Inca cognition of Landscape: archaeology, etnohistory, and the aesthetic of alterity. En Archaeologies of Landscape. Contemporary perspectives, editado por W. Ashmore y A.B. Knapp, pp. 149-168. Blackwell Publishers, Oxford.

Vilches, F.

1999 Inka Rock Art?: Minor Arts, Major Meanings. Thesis submitted in partial fullfillment of the requeriments for the degree of Master of Arts, University of Maryland.

Vilches, F. y M. Uribe

1999 Grabados y pinturas del arte rupestre tardío de Caspana. Estudios Atacameños 18:73-87.

Williams, V.

2003 Provincias y capitales. Una revisita a Tolombón, Salta. Ponencia presentada en el $51^{\circ}$ Congreso Internacional de Americanistas, Santiago, Chile. 